\title{
Collaborative concept mapping with reciprocal kit-build: a practical use in linear algebra course
}

Lia Sadita ${ }^{1 *}$ D, Tsukasa Hirashima ${ }^{1}$, Yusuke Hayashi ${ }^{1}$, Warunya Wunnasri ${ }^{2}$, Jaruwat Pailai ${ }^{3}$, Kasiyah Junus $^{4}$ and Harry Budi Santoso ${ }^{4}$

\author{
*Correspondence: lia@lel.hiroshima- \\ u.ac.jp \\ ${ }^{1}$ Learning Engineering Laboratory, \\ Department of Information \\ Engineering, Hiroshima University, \\ Hiroshima, Japan \\ Full list of author information is \\ available at the end of the article
}

\begin{abstract}
The design of interactions among peers plays a key role in collaborative learning. Various strategies have been applied to assist learners in collaborating and creating a continuous effort to construct and maintain shared knowledge, such as utilizing a concept map as a representational tool during discourse. Some previous studies have revealed its positive effect on both the learning achievements and the attitudes of the students. A strategy for improving the quality of explanation of the students during collaborative concept mapping is to enable them to externalize their thinking in their private spaces beforehand. However, students may face difficulties when they need to integrate their individual propositions with the group concept map. This study employs the reciprocal kit-build (RKB) approach to help students externalize their ideas, understand and clarify their partners' perspectives, integrating with their comprehension, hoping they can construct a high-quality collaborative product. The study is conducted in a linear algebra class in an Indonesian university. The effect of the RKB as learning activities on the group outcomes is evaluated. How students change their propositions, from the individual to the collaborative phase, following the visualization of the difference map provided by the RKB system is also presented. Perceptions of the students during these activities are examined to measure the effectiveness of the approach from the viewpoints of the participants. The findings convey that the RKB is promising for learning in a collaborative context despite some limitations in the practical classroom experimental settings.
\end{abstract}

Keywords: Collaborative concept map, Kit-build, Collaborative learning, Co-construction of knowledge

\section{Introduction}

Collaborative learning is defined as a situation in which two or more people attempt to learn something together (Dillenbourg 1999). In line with the Social Constructivist Theory of Vygotsky (1978), some previous researches have attached great importance to the students' interactions as a fundamental role in collaborative learning (Baines et al. 2009; Webb 2009). The collaboration does not merely happen just because individuals are co-present (Baines et al. 2009; Roschelle and Teasley 1995; Webb 2009).

(c) The Author(s). 2020 Open Access This article is licensed under a Creative Commons Attribution 4.0 International License, which permits use, sharing, adaptation, distribution and reproduction in any medium or format, as long as you give appropriate credit to the original author(s) and the source, provide a link to the Creative Commons licence, and indicate if changes were made. The images or other third party material in this article are included in the article's Creative Commons licence, unless indicated otherwise in a credit line to the material. If material is not included in the article's Creative Commons licence and your intended use is not permitted by statutory regulation or exceeds the permitted use, you will need to obtain permission directly from the copyright holder. To view a copy of this licence, visit http://creativecommons.org/licenses/by/4.0/. 
Instructional strategies attempted to employ scripts, scenarios, or representational tools for encouraging the learner to collaborate.

In collaborative learning, individual learners need to make a continuous effort to construct and maintain group-shared knowledge (Roschelle and Teasley 1995). They may have forgotten prior discussion or feeling difficult to remember what they have discussed or co-constructed (Jeong and Hmelo-Silver 2016). An external representation tool assisted the learner in articulating and maintaining shared focus during discourse (Fischer et al. 2002; Suthers 2006; van Boxtel et al. 2002). A concept map has been mainly utilized as a representational tool in a collaborative setting to facilitate group discussion, as well as to communicate complex ideas (Fischer et al. 2002; Gracia-Moreno et al. 2017; Suthers 2006; van Boxtel et al. 2000).

A concept map is a graphical tool for organizing and representing knowledge which consists of concepts and relationships among these concepts to facilitate meaningful learning (Novak and Cañas 2008). In a concept map, the nodes represent concepts, while the links with its descriptive labels explain the relationships among the concepts. Coconstruction of a concept map is an effort to co-create a representational tool of group understanding. It allows learners to be consistent and gain convergence, rather than just through a dialogue (Jeong and Hmelo-Silver 2016; Roschelle and Teasley 1995).

Previous research on collaborative concept mapping has extended the prior activity by creating an initial design of a concept map individually to trigger more questions and conflicts among learners (van Boxtel et al. 2000). This individual preparatory phase contributed to promoting awareness of own understanding and limitations, better explanation, and more elaboration (de Weerd et al. 2017; Gracia-Moreno et al. 2017; van Boxtel et al. 2002). However, learners also faced difficulty in integrating different ideas while creating a map collaboratively in a public space. In a study conducted by GraciaMoreno et al. (2017), more than half of the individual nodes were not transferred to the group public space, and the students were in tendency to refuse other ideas through online medium without asking for confirmation.

The study proposes an approach to see the perspective of others before co-creation of concept map by reconstructing the partner's map and discussing the similarities and differences of two maps with the reciprocal kit-build (RKB) system (Wunnasri et al. 2018a). After students externalize their thinking and understand the partners' perspectives, they are expected to build a shared understanding and find a better solution for the problem task. The purpose of this study is to identify the effect of the RKB approach on collaborative concept mapping in a practical classroom. A linear algebra class is selected as the study subject since the class implemented various collaborative learning approaches for both in-class and online activities. The research questions of the study are as follows: Does the RKB approach affect co-construction of knowledge with concept maps? If so, to what extent? The study focuses on identifying the effectiveness from the end-products (collaborative maps), the patterns of map changes from individuals to groups, and the perceptions of the students while following the learning activities.

\section{Related works}

\section{Collaborative concept mapping}

Fischer et al. (2002) divided collaborative learning process into four stages: externalization of task-relevant knowledge, elicitation of task-relevant knowledge, 
conflict-oriented consensus building, and integration-oriented consensus building. Using a concept map as a visualization tool in collaborative learning has the potential to support all these processes. The externalization of abstract concepts and the relationship between them can serve as a common ground to ensure that interaction partners understand each other (Jeong and Hmelo-Silver 2016; Roschelle and Teasley 1995). This representation may trigger a question and lead to elicitation of knowledge (Fischer et al. 2002) because students' thinking turns into explicit for sharing and misinterpretation can be clarified (Beers et al. 2006; Correia et al. 2008). The concept map also reduces the ambiguity of utterances and different views is easily recognizable resulting in cognitive conflicts and negotiation of meaning to reach a consensus (Chiu et al. 2000; Fischer et al. 2002; Gao et al. 2013; Jeong and Hmelo-Silver 2016; Stahl et al. 2006; Wang et al. 2017).

Some previous researches have examined the effect of collaborative concept mapping on attitudes. Their findings postulated that collaborative concept mapping can facilitate group motivational-emotional experiences and reduced participants' anxieties (Czerniak and Haney 1998), increasing group motivations (Beers et al. 2006). Students took more responsibility for learning (van Boxtel et al. 2002), while the quantity of group interaction is significantly correlated to the group concept mapping performance (Chiu et al. 2000). In summary, studies posited that concept mapping has a positive effect on both students' attitudes and learning achievements (Basque and Lavoie, 2006; Czerniak and Haney, 1998).

Before creating a concept map collaboratively, some studies suggested an individual preparation phase by creating a design of the concept map in the learners' own private spaces (de Weerd et al. 2017; Gracia-Moreno et al. 2017; van Boxtel et al. 2000). By designing an initial map individually, students had time to reflect, organize, and develop their understanding which leads to better explanation during the discussion (Gao 2008; Gracia-Moreno et al. 2017; van Boxtel et al. 2000). They also asked more questions and demonstrated more openness exhibited to group contributions because they were allowed to elicit information that is relevant to their ambiguity from their partner (de Weerd et al. 2017; Gao 2008; van Boxtel et al. 2002). Furthermore, the groups with individual preparation outperformed the group without preparation in their post-tests (van Boxtel et al. 2000).

Students in the individual preparation group encountered difficulties in sharing developed ideas and integrating them into public knowledge in the group map (Gracia-Moreno et al. 2017; van Boxtel et al. 2000). When students worked in a personal workspace, they preferred refusing others' ideas by deleting them directly in the digital space instead of opposing them through talk (Gracia-Moreno et al. 2017). Furthermore, the externalization of students' thinking is an important requirement to find misrepresentation. When students' knowledge is visible, they can exchange their own understanding and track similarities and differences between each other's representation. At this stage, students may face socio-cognitive conflicts that are considered necessary for conceptual changes in collaborative learning (Limon 2001; Nastasi and Clements 1992). Socio-cognitive conflict is defined as an interaction, active engagement of participants in a cognitive controversy or confrontation leading to points of view, interpretations, different solutions, which makes group members overcome the differences together and come up with joint solutions (Iancu 2014). Based on those recommendations, the 
current study highlights that concept map sharing and negotiation activities have the potential to foster conceptual changes. Active inquiry to resolve conflicts is one of the critical roles in knowledge construction, which can increase the number of sharedknowledge that all group members had after collaboration (Beers et al. 2006; Chan et al. 1997; Chen et al. 2018; Kalishman et al. 2012; Roschelle 1992; Roschelle and Teasley 1995; van Boxtel et al. 2000).

When students' prior knowledge is shared, they can be aware of the partners' understanding, which is essential to reduce miscommunication (Nickerson 1999). When knowledge of a partner's information is lacking, a self-heuristic is applied to estimate the knowledge of others, i.e., using one's knowledge. Imputing one's knowledge to others may result in overestimation, a situation when speakers expected the audience to know everything they know (Nickerson 1999). Sharing the partner's concept map and the access to a resource underlying this knowledge improved the efficiency of knowledge co-construction because students did not need to collect information and able to directly start the problem-solving process (Engelmann and Hesse 2010).

\section{The KB concept mapping approach}

The Kit-Build (KB) is a re-constructional closed-ended approach to concept mapping activity in which students construct a map based on predefined nodes and links extracted from an expert's map (Hirashima et al. 2011; Hirashima et al. 2015). Figure 1 illustrates the activity between a teacher and his/her students during KB concept mapping. Given the set of unconnected map components, the students need to find out the map structure. After the students upload their maps, the KB system will perform a propositional-level similarity measure and show the comparison results in the $\mathrm{KB}$ analyzer as feedback to the teacher. The analyzer displays three types of links: matching link, excessive link, and lacking link. A matching link represents that the student creates the same proposition as appeared in the expert map, an excessive link indicates that students create a new proposition that has not been defined by the teacher, while a

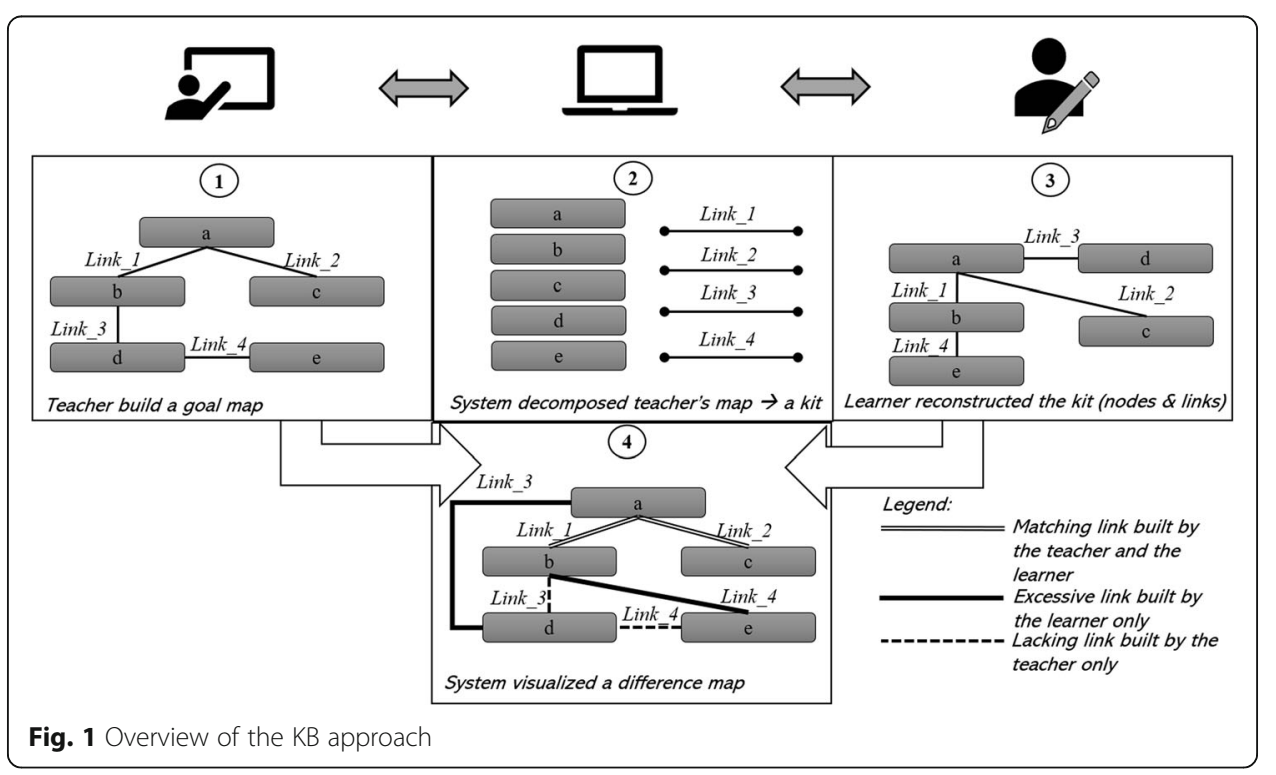


lacking link illustrates a teacher's proposition that is not reconstructed by the students. The teacher use this information to assess learners' understanding of the given materials, identify students' misconceptions, and adjust the next instructional strategy (Yoshida et al. 2013; Hirashima et al. 2015; Kitamura et al. 2016; Hayashi et al. 2017; Pailai et al. 2017).

The current study extended the use of the $\mathrm{KB}$ approach to support communication and build shared knowledge between a pair in a computer-supported collaborative learning setting. Unlike the standard KB, a dyad in the RKB has a similar level of expertise (novice-novice), and each group member is allowed to define the initial map. The initial map components are decomposed to be reconstructed by the collaborating partner. Subsequently, the RKB system performs similarity matching between the initial map and the partner's reconstructed map. The similarity results, in the form of matching, excessive, and lacking links, are then presented to the learners to aid group discussion afterward. This approach allows students to externalize their thinking in a private space, elicits knowledge of partners, and resolves conflict through visualization of a difference map. By doing so, students had the opportunity to reflect their thinking on their maps as well as their partners' maps. Thus, incorrect notions became fine-grained and challenging, which is necessary to improve the quality of the final concept map (Roth \& Roychoudhury, 1993). Inducing cognitive conflict by presenting anomalous data or contradictory information is one of the most common teaching strategies regarding conceptual change implemented in the classroom (Limon, 2001).

Initial studies of the RKB approach showed that it promoted productive discussion between partners compared to the group without reconstruction and difference mapsupported discussion (Wunnasri et al. 2018a). The RKB map also encouraged the pair of partners to understand each other based on the similarity score of the individual's map after discussion (Wunnasri et al. 2018b). Their findings demonstrated that the RKB can be used to share understanding as preparation for collaboration. However, they have not evaluated the effect of applying this approach to collaborative knowledge building, so far. Hence, the study evaluated the collaborative product (group map) after the discussion guided by the KB visualization. The current study is also implemented in a practical classroom and gains the perspectives of the participants.

\section{Methods}

\section{Participants and context of the study}

The unit of analysis of the study was Computer Science (CS) students from a large public university in Indonesia $(n=44)$. Since all students were belong to the Faculty of Computer Science, more male students were included in this research $(n=32)$. Most participants were freshmen $(n=39)$ in their second semester. They worked in groups of two, which were freely selected by the students so that they could work on the task conveniently. When students worked in a small group, they exhibited structures and leadership to sustain the continuity of the discourse and regulated their cognitions more than in a general class discussion (Junus et al. 2014). Group randomization could not always be applied for the experiment in a practical classroom. Randomization of group members would be necessary to ensure the fairness of the treatment for all participants; however, based on suggestions from the responsible class teacher, the 
students were allowed to choose their own pair so that they would not be reluctant to collaborate.

This study was carried out on a core subject in Computer Science and Information System major named Linear Algebra which is a substantive core subject for undergraduate students. However, since the experiment was not conducted on its regular term, only one course was offered. This course provides students with the skill to solve problems related to vector and matrix algebra, as well as to develop mathematical reasoning skills (clarity, consistency, and logic). Problem-solving skills are essential to advance learning in CS-related topics. To achieve these learning outcomes, the teacher implemented the constructivism and student-centered learning approach during the 14 weeks course period. Both face-to-face and online courses were utilized as the learning environments. The students were engaged in various collaborative learning activities such as online discussion, think-pair-share, and jigsaw technique.

A preliminary study of students' preparedness level in the computer-based learning environment from the previous classes revealed that students had a good technological competency, a moderate competency in interaction with learning content, but lacked interaction skills with their learning community (Kasiyah et al. 2017). Therefore, the use of concept maps for expressing students' ideas and as a common ground during discussion aligned with the teacher's previous challenges on similar classes. Moreover, the students were familiar with map building concepts, since the teacher had modeled concept map creation, as well as asked the students to create their maps after she finished a topic.

The experiment was conducted in a laboratory where students might choose to use the provided computers or their laptops. The students were placed side by side in pairs (Fig. 2). The results of this experiment were accepted as a part of the mid-term exams. A single group study design was employed in the class since the results will affect the final grades of the students who completed the course.

\section{Learning topics and activities}

In this study, students were requested to create a concept map individually and collaboratively. There were two lessons covered in the concept map, which are general vector space and inner product space. Some learning objectives of these courses were as follows: students can explain general vector space, identify a set that is a vector space, and explain the definition of inner product function and inner product space.

During high school, the students became familiar with the concept of the vector in $R^{2}$ and $R^{3}$, but not in a more abstract space such as matrices or differential functions

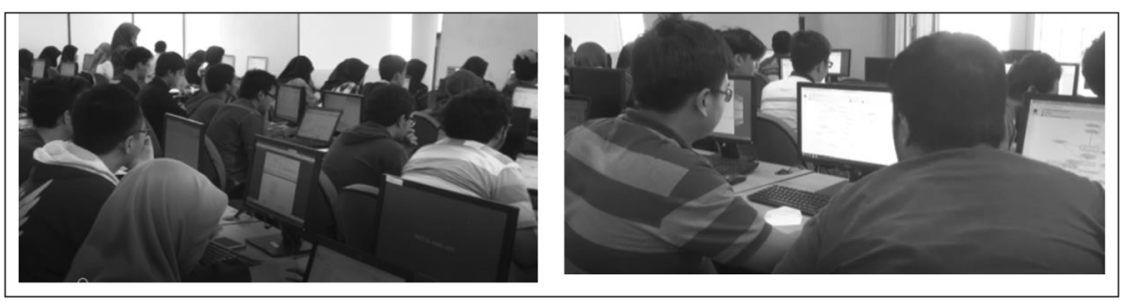

Fig. 2 The classroom settings during the experiment 
over $[a, b]$ space. After completing these topics, students were expected to do accommodation from the concept of a vector as an entity with length and magnitude, to a vector as an element of vector space with the length and magnitude that calculated based on the defined inner product space. Students were also expected to understand that an inner product function is a function that maps $V \times V$ to $R$ and must satisfy the following four axioms: additivity, homogeneity, positivity, and symmetry. The axioms are preconditions for defining an inner product function. It should be attached to the function, not to a space $V$.

Before giving assignments to the students, the teacher wrote a concept map that involved essential concepts in these lessons. It consisted of fifteen nodes and fourteen links (Fig. 3). The nodes were extracted and became predefined nodes for the students. The students had to find the relationships between those concepts (nodes) and provided linking words by themselves. The nodes were as follows: vector, vector space, inner product space, directed line segment, additivity axiom, homogeneity axiom, positivity axiom, symmetry axiom, domain: $V \mathrm{x} V$, codomain: $R$, inner product function, orthogonal projection, the distance between two vectors, length of a vector, and the angle between two vectors.

During the experiment, the students used a web-version of the RKB system (Fig. 4). Before the session, a video tutorial on how to use the system was presented to the students. A brief tutorial about concept mapping activity and how to create a simple map with the KB system was provided at the beginning of the experiment to ensure they were familiar with the assignment and the system.

The experiment was administered for about $2 \mathrm{~h}$ and divided into two phases: individual phase and collaborative phase. The students created an initial map phase (25 min) and reconstructed a KB map, given a set of unconnected nodes and links (kit) from their partner's maps (20 min), in the individual phase. They conducted a discussion facilitated by visualization of the similarities and differences between the two maps (10 min) and created a group map collaboratively $(30 \mathrm{~min}$ ) during the collaborative phase. Figure 5 depicts the activities and samples of outcomes in every phase.

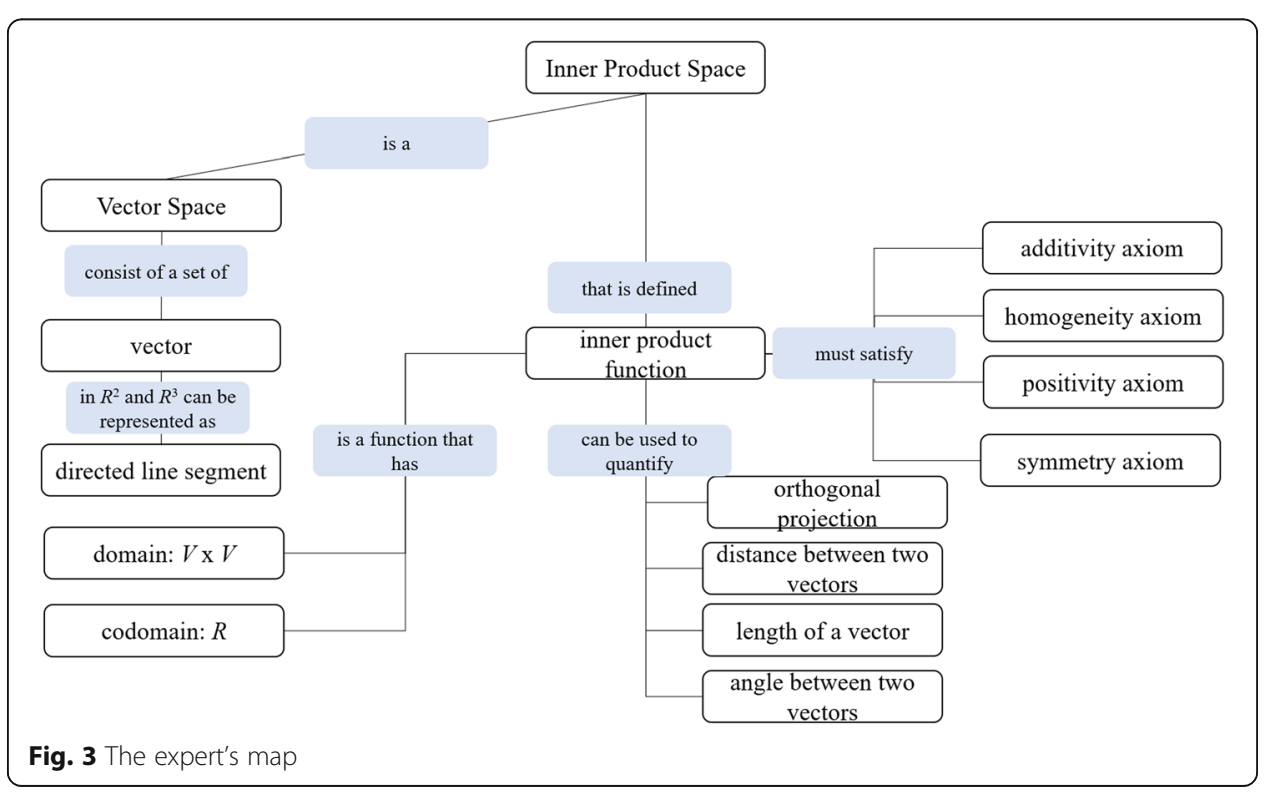




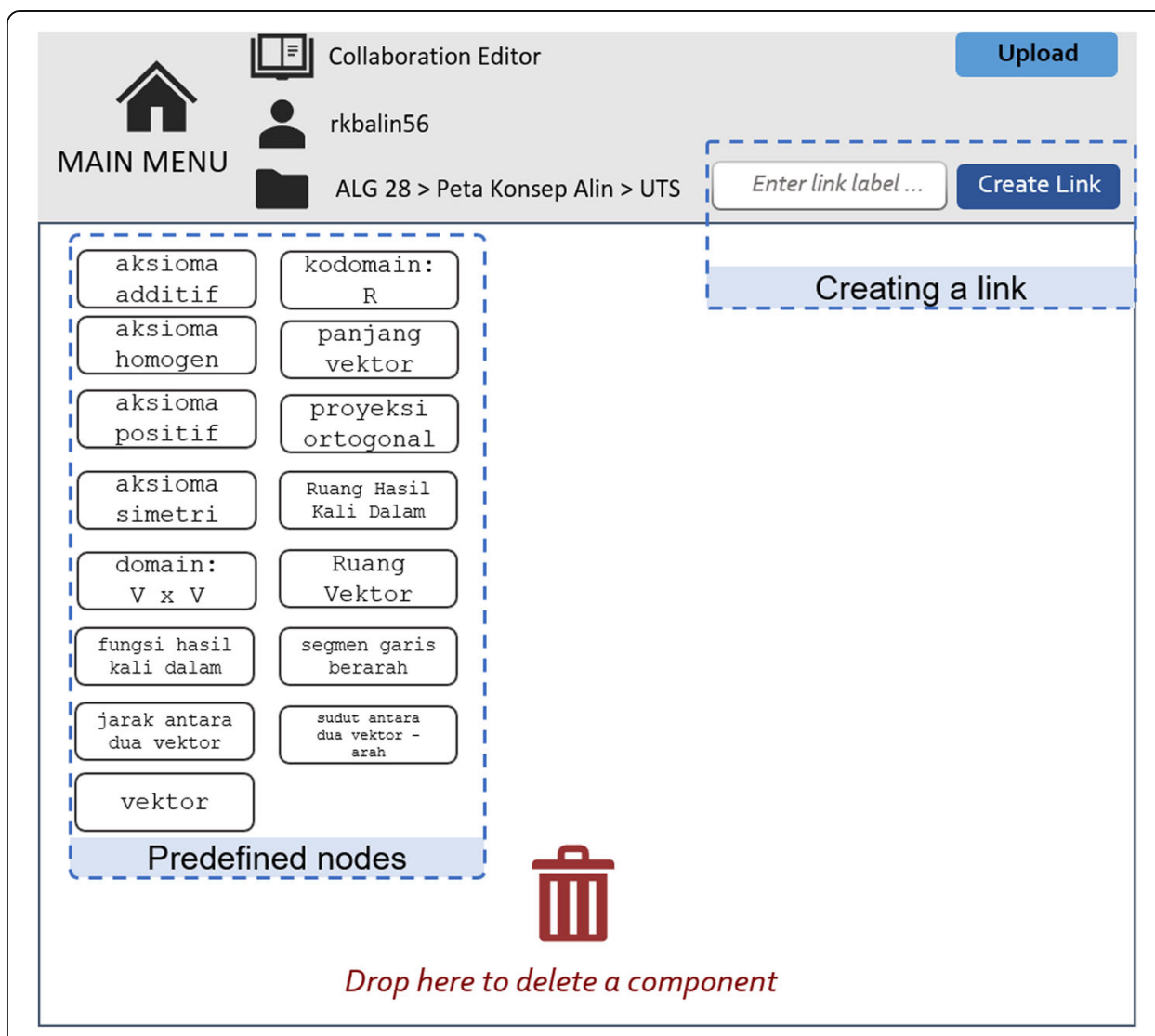

Fig. 4 The user interface to create an individual map or a group map

At the first individual phase, the students received predefined concepts (nodes) and were required to define the links (connection) between those concepts which enabled them to express their own understanding. The nodes were already defined by the teacher in the expert's map (see Fig. 4). The availability of the initial nodes served as key concepts that enabled participants to brainstorm other related concepts and proceed more efficiently (Gao 2008). The students could not add a new node to help them maintain shared focus during discussion, but they could leave out some irrelevant nodes (if any). Next, a set of unconnected nodes and links extracted by the system from each individual map was presented only to their partners. Each partner was then requested to build a new map based on those components, which is called the KB map.

After this reconstruction activity, the system performed a propositional-level exact matching to identify the similarities and differences between the initial map and the KB map. The system compared the connecting line (links) as well as the linking words that defined the relationship between two nodes. Afterward, each group conducted a discussion guided by difference map visualization, consisting of matching links, excessive links, and lacking links. The matching link represents that the partner connected the same link and linking words as in the initial map. While the excessive link denotes a new connection that only appeared in the partner's map and the lacking link signifies initial linking words that could not be reconstructed by the partner. Subsequently, to finalize the learning activity outcomes, each group constructed a single concept map collaboratively. The latest phase demanded more time since several groups needed 


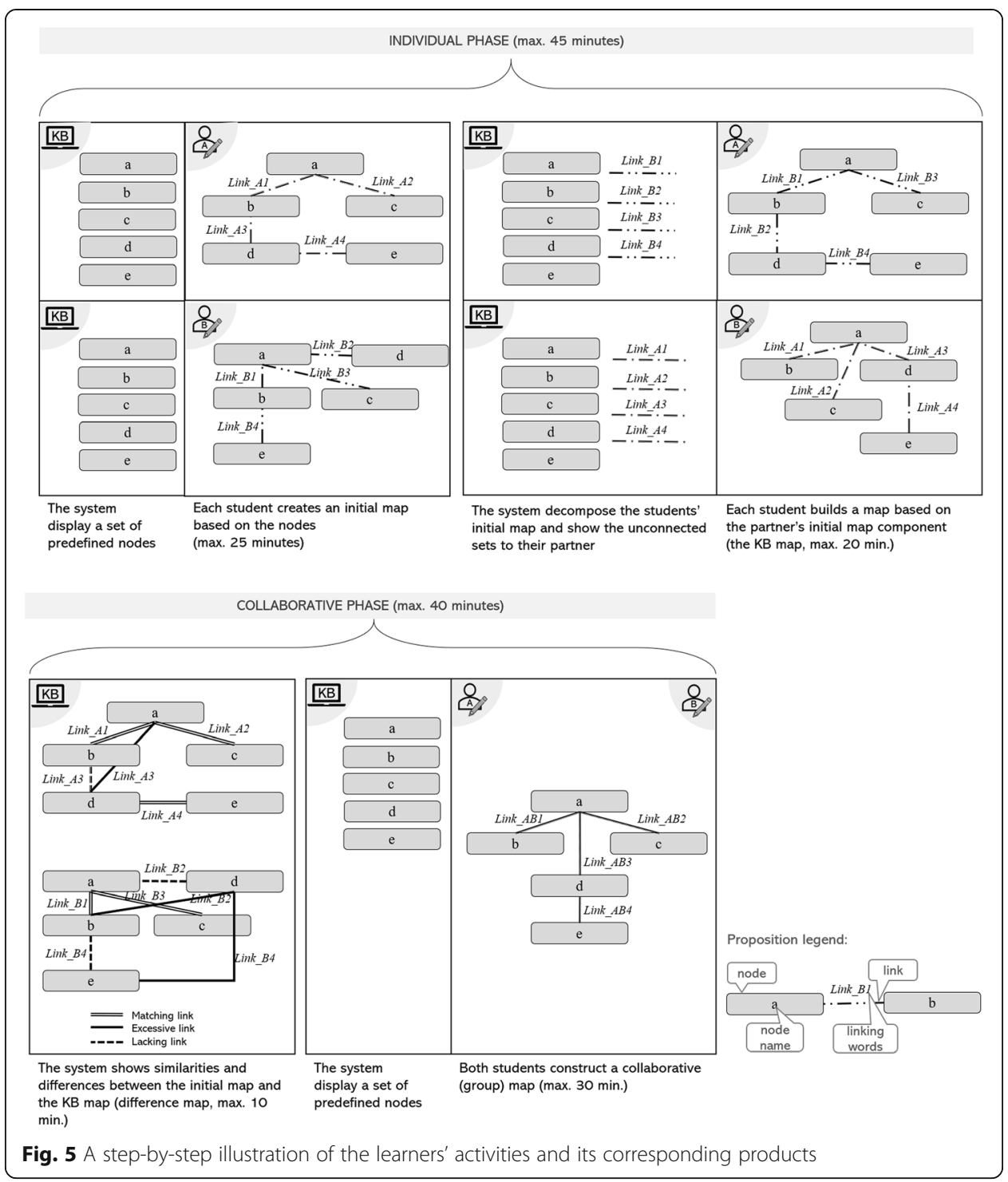

extra time to conclude their final works, while some others had finished their task earlier. Other learning resources such as course slides, the Internet, or textbook were open to the students and they were allowed to read and use them.

After the experiment, the teacher provided feedback to students in the classroom. During the feedback session, the teacher explained the most common mistakes that appeared in the maps and showed some examples of the correct propositions. The feedback session was valuable because the students were informed of their misconceptions, and they learned how to build a good concept map. This session was held within 30 $\min$.

\section{Data collection and analysis}

The RKB system recorded all students' individual maps, KB maps, and group maps. As in a common classroom, the teacher evaluated the students' individual and group maps. The similarities between the individual and the group maps might be an indicator of individual inputs to the group achievements, therefore similarities 
of propositions written in those maps were identified. Visualization in KB analyzer (e.g., matching, lacking, and excessive links) was used to categorize the similarities of propositions. In addition, a survey delivered after the experiment was analyzed to gain the perceptions of the participants.

\section{Concept map scoring}

The teacher developed a grading rubric to evaluate students' concept maps that used the expert's map as a criterion map (Osmundson et al. 1999). The teacher categorized the types of information that should be included in the map, not merely a propositionallevel matching. Therefore, it did not rule out the possibility that there is a variation on the map structure or the linking words which presented similar information (Chung et al. 1999). This scoring procedure involved comparing the similarities between students' produced maps and the expert's map, regarding the map contents and structures, which also has been practiced in other concept mapping studies (C. H. Chiu 2004; Chiu et al., 2000; Chiu et al. 2000; Kinchin et al. 2005). Such a scoring approach is reliable to measure domain-specific knowledge with a strong positive correlation to other content knowledge measures such as writing task (Herl et al. 1996).

Moreover, the teacher has considered students constructed propositions when finalizing the rubric. A full score was given to the map which contains all relations with correct linking words. A zero score was given to any proposition when the essential link (relation) was unavailable, or the linking words were not defined correctly. Every mistake will get a penalty based on the error type (Table 1).

\section{Proposition similarity}

Every student constructed a concept map three times, both individually and collaboratively. The study identified how students transfer their individual propositions to form group propositions. A propositional-level matching was utilized to identify the similarity between these propositions. First, the same relationship (connecting line) between the individual maps, KB maps, and group maps was identified. If both maps had the same connecting line, the linking words were taken and pre-processed by normalizing the text to lower case, removing punctuations, and stemming. Next, cosine similarity matching between the represented vectors of the linking words was applied to finalize the process. The same linking words means that they had a similarity score of 1 .

Table 1 Type of proposition error

\begin{tabular}{lll}
\hline $\begin{array}{l}\text { Type of } \\
\text { error }\end{array}$ & Description and example & $\begin{array}{c}\text { Minus } \\
\text { point }\end{array}$ \\
\hline Fatal error & $\begin{array}{l}\text { The students did not draw an essential link between the two nodes. } \\
\text { The students created a wrong definition, e.g., the vector was defined as a directed line } \\
\text { segment; the domain and codomain were linked to the inner product space/general } \\
\text { vector space, not to the function; a vector space was defined as a subspace of an } \\
\text { inner product space. }\end{array}$ & -10 \\
Moderate & $\begin{array}{l}\text { The students connected a partially incorrect relation, e.g., the measurement-related } \\
\text { error }\end{array}$ & $\begin{array}{l}\text { nodes were connected to the vector and not to the inner product function; the } \\
\text { axiom-related nodes were connected to the inner product space, not to the inner } \\
\text { product function. }\end{array}$ \\
Minor error & $\begin{array}{l}\text { The students described partially incorrect linking words, but the relation was correct, } \\
\text { e.g., a "must" word was not included when defining a relation to the axioms. }\end{array}$ & -2 \\
\hline
\end{tabular}




\section{Questionnaire}

After the experiment, a survey questionnaire was conducted to examine the students' perspectives on the RKB approach for creating a collaborative concept map. The questions were designed based on the preliminary results of the experiment. The survey covered items regarding the perspectives of the students on the task itself (e.g., attractiveness and stimulation scales) and the system used (or non-task; e.g., perspicuity scale). The questionnaire scales were adopted from the User Experience Questionnaire, an Indonesian version (Laugwitz et al. 2008; Santoso et al. 2016). Since the aim of the study was to examine the perceptions of the students on every stage of the study approach, only three representative items were selected which were repeated for each stage (Fig. 6). The final sub-scales of the study consisted of 15 close-ended items (Table 2), where students were requested to rate the response set from 1 to 7 scale (left-to-right), and answer open-ended questions. The six open-ended questions were given to uncover the positive and negative experiences of the students during the experiment (e.g., "Mention the most interesting moments encountered while you were asked to create a concept map from your friend nodes and links," "Mention (if any) any obstacle encountered when you were asked to create a concept map from your friend nodes and links"). All questionnaire items had been face-validated by the teacher before distribution to the students. Cronbach's alpha coefficients were $0.74,0.84$, and 0.77 for attractiveness, stimulation, and perspicuity subscales, respectively, showing good internal consistency.

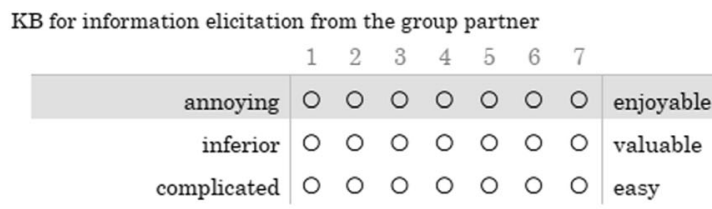

The process of expressing ideas in the form of a concept map

6. Mention (if any) any technical and non-technical difficulty encountered while you were using Kit Build to express ideas in the form of a concept map? (1)

The process of exchanging nodes and links with a partner

7. Mention the most interesting moments encountered while you were asked to create a concept map from your friend nodes and links.
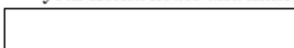

8. Mention (if any) any obstacle encountered when you were asked to create a concept map from your friend nodes and links

Fig. 6 A sample of closed- and open-ended questions 
Table 2 Closed-ended item categories

\begin{tabular}{lllll}
\hline Context (category) & Item code & Left & Right & Scale \\
\hline $\begin{array}{l}\text { KB for expressing ideas/understanding of learning } \\
\text { materials }\end{array}$ & Expldea_A & Annoying & Enjoyable & Attractiveness \\
& Expldea_S & Inferior & Valuable & Stimulation \\
& Expldea_P & Complicated & Easy & Perspicuity \\
KB for information elicitation from the group partner & Elicit_A & Annoying & Enjoyable & Attractiveness \\
& Elicit_S & Inferior & Valuable & Stimulation \\
& Elicit_P & Complicated & Easy & Perspicuity \\
KB for understanding the ideas of the partner & Understand_A & Annoying & Enjoyable & Attractiveness \\
& Understand_S & Inferior & Valuable & Stimulation \\
& Understand_P & Complicated & Easy & Perspicuity \\
KB for discussion with the support of visualization & Discuss_A & Annoying & Enjoyable & Attractiveness \\
(figure) of the concept map differences & Discuss_S & Inferior & Valuable & Stimulation \\
& Discuss_P & Complicated & Easy & Perspicuity \\
KB for integrating ideas in a group & Integrate_A & Annoying & Enjoyable & Attractiveness \\
& Integrate_S & Inferior & Valuable & Stimulation \\
& Integrate_P & Complicated & Easy & Perspicuity \\
\hline
\end{tabular}

\section{Results}

\section{Overall group performance}

This section of the study revealed how the quality of concept maps varied from the individual to the collaborative phase. The central tendency of individual and group concept maps was illustrated in Table 3. A paired-samples t-test was conducted to compare individual and group map scores. The results of the group maps $(M=90, S D$ $=7.31)$ showed increasing scores compared to individual maps $(M=72.21, S D=$ 18.22), $t(20)=4.92, p<.01$. The observed standardized effect size was large (Cohen's $d$ $=.87)$. The standard deviation $(S D)$ of group map scores also became lower, compared to individual scores. Some prior studies also used group maps to measure the effect of concept mapping in computer-supported learning on task performance (Chiu et al. 2000; Stoyanova and Kommers 2002).

Figure 7 depicts the differences between the averages of individual scores and the group map scores. A positive value shows an increasing score while a negative value represents otherwise. Eighteen out of 22 groups increased their scores, 3 groups got a similar score, while 1 group decreased their scores. Furthermore, the group ALG 18 was omitted from the analysis because the individual and group maps received full marks (100 points).

Changes of concept map quality were indicated from the decrease of errors in the group propositions (Table 4). The percentage of false propositions was reduced from 36 to $19 \%$. Specifically, there was a change from the number of false propositions with

Table 3 Descriptive statistics of individual- and group-map scores

\begin{tabular}{lll}
\hline & Individual-map score & Group-map score \\
\hline Average & 72.21 & 90 \\
SD & 18.22 & 7.31 \\
Minimum & 41.43 & 75.71 \\
Maximum & 98.57 & 100 \\
\hline
\end{tabular}




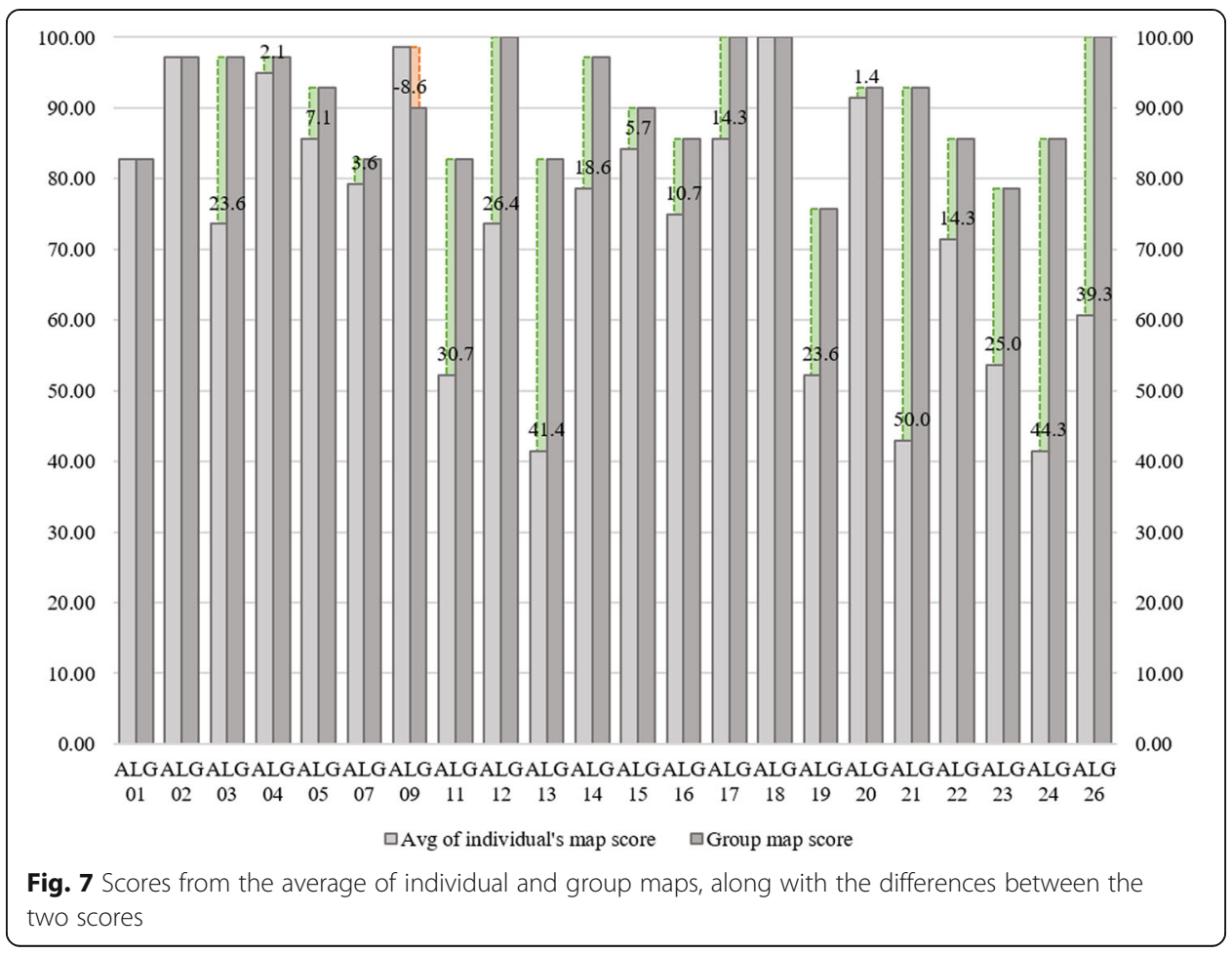

fatal errors. The reduction of fatal error propositions affected the increasing number of true propositions or moderate/minor error propositions.

Figure 8 shows an example of a set of maps generated by group ALG 12 during the individual and collaborative phases. The main difference between the initial maps is the Individual 1 connected the measurement-related concepts (e.g., length of vector, angle between vector, distance between vector, and orthogonal projection) to the inner product space, while the Individual 2 linked between the measurement-related concepts to the inner product function. The KB maps were reconstructed based on the initial map components. The similarities and differences between the initial maps and the reconstructed maps were visualized to aid learners during the discussion. Finally, in the group map, they created the links as in the Individual 2's map, which is similar to the teacher's map (Fig. 3).

\section{The pattern of students' propositions from the individual map to the group map}

The process of knowledge co-construction was preceded by the externalization of individual knowledge and the sharing of ideas between partners through concept maps reconstruction. During the experiment, students did not receive any feedback from the teacher, but they could read other learning resources such as textbooks, course slides,

Table 4 Distribution of correctness level in all individual and group propositions

\begin{tabular}{lll}
\hline Level of correctness & Individual-map (\%) & Group-map (\%) \\
\hline The true proposition & 64 & 81 \\
The false proposition with a minor error & 5 & 7 \\
The false proposition with a moderate error & 10 & 7 \\
The false proposition with a fatal error & 21 & 5 \\
\hline
\end{tabular}




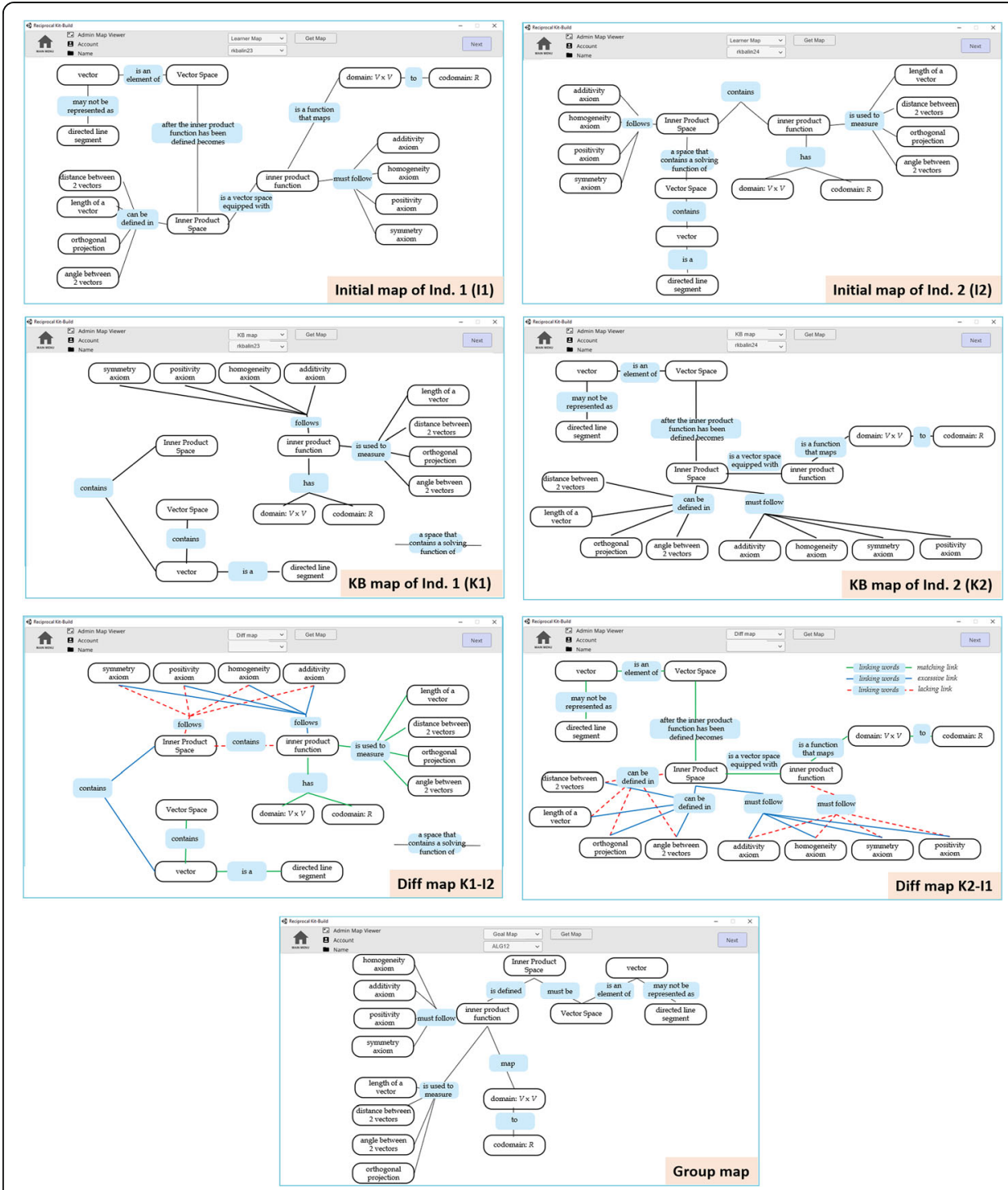

Fig. 8 Sample of individual maps and group map generated by group ALG12

or the Internet. This section explained the results obtained from students' propositions in every stage.

In the initial stage, all students wrote 582 propositions. From these propositions, the partner constructed $75.26 \%(n=438)$ matching links and $24.74 \%(n=144)$ lacking links. Based on the number of matching links, the students could reconstruct most of the propositions that originated from their partner's map, which implied that they could find the initial maps structures. The number of excessive links as many as 141, which means that there are three lacking links that did not become new propositions. The presences of the excessive and lacking links indicated that there were misunderstandings or disagreement between the group members.

It was then identified how students follow the visualization of the RKB links in the group propositions. When constructing a map collaboratively, all group members can determine whether they will use the same proposition as in the individual map, preserve the relation (connecting line) but modify the linking words, or create a different 
proposition. Figure 9 shows how the students adopted these reconstructed links to compose group propositions. Most matching links have included in the group propositions with the same connecting line $(81 \%, n=354)$. Most of the excessive links $(60 \%, n$ $=84$ ) were used to compose group propositions, but more than half of the lacking links were not used. The students modified the linking words from matching links, lacking links, and excessive links with portions of $56 \%, 22 \%$, and $47 \%$, respectively.

\section{$\mathrm{KB}$ visualization and group performance on the task}

As mentioned above, the individual propositions written in the initial and KB maps were generally adopted to become group propositions. In this section, the distribution of the correctness level of follow-up propositions in the group map was presented. Figure 10 reveals that these propositions are mainly correct. Students thought deeply about the propositions and found out the correct representation. Besides, Pearson's correlation analysis depicted that there was a moderate positive correlation between the score differences and the number of excessive links presented in the KB analyzer $(R(21)=0.58, p<.01)$.

\section{Students' perceptions of the RKB approach}

Figure 11 displays the results of closed-ended items. Overall, students considered that this activity was valuable, rather than inferior (stimulation scale), and more enjoyable, rather than annoying (attractiveness scale). Though the items related to perspicuity (complicated

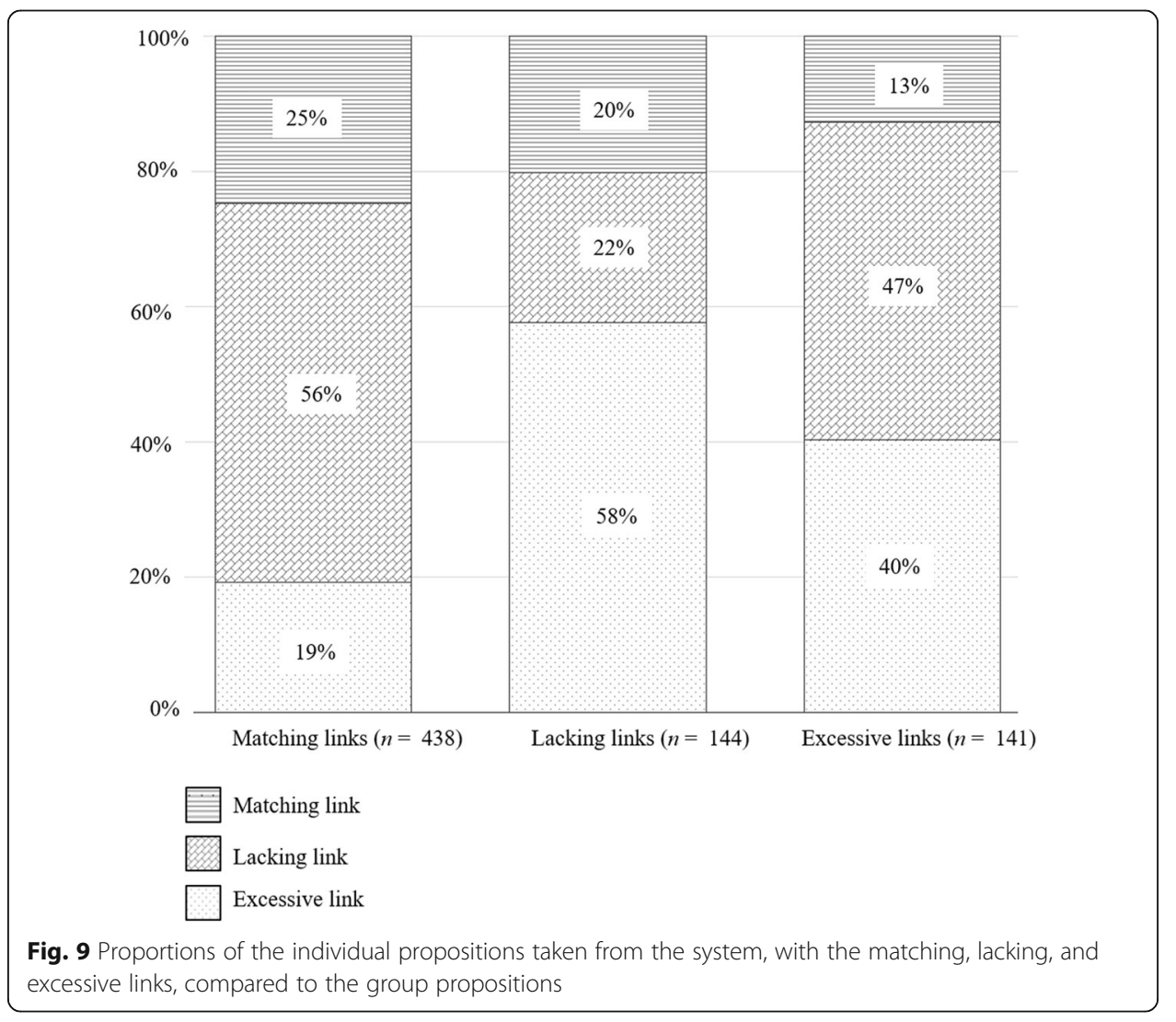




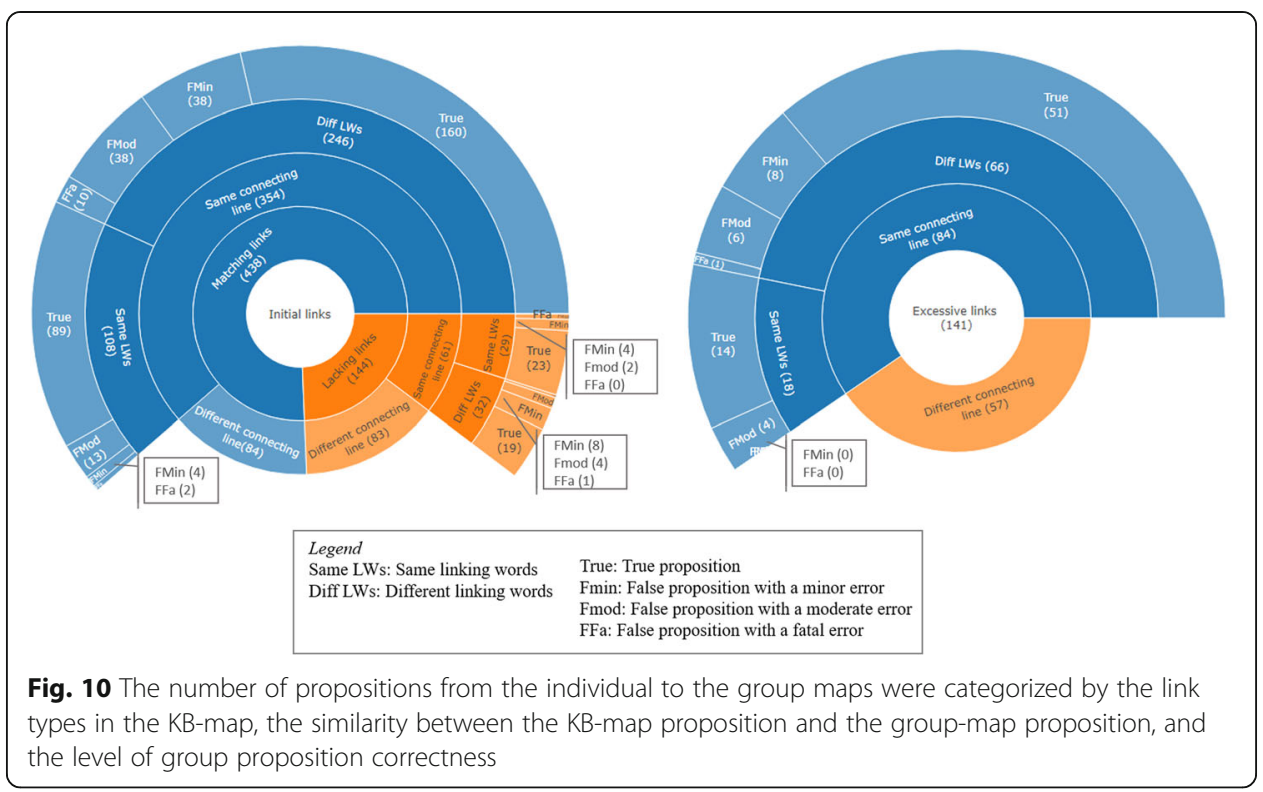

vs. easy) had the lowest ranks among others, the mean scores of those items were above 5.00. The perceptions of the students revealed that the KB was valuable for integrating ideas in a group, eliciting information from the partner, and discussing differences in ideas. Consistently, these three activities were getting the highest scores on the attractiveness scale. The students also found that discussion and integration were the most complicated parts, along with understanding the comprehension of their partners.

Based on the open-ended questionnaire, more than half of the students (60\%) agreed that the most attractive phase was the phase when they could see the difference between the initial concept map and the reconstructed map (e.g., "I was glad to see the different way to connect the nodes by my friend"). The KB visualization of difference map also helped them to realize their mistakes (14.9\%, e.g., "I realized if I have misconceptions or incorrect notions") and made them understand the comprehension of their partner $(8.9 \%$, e.g., "I need to guess and try to understand perspectives of my friend's

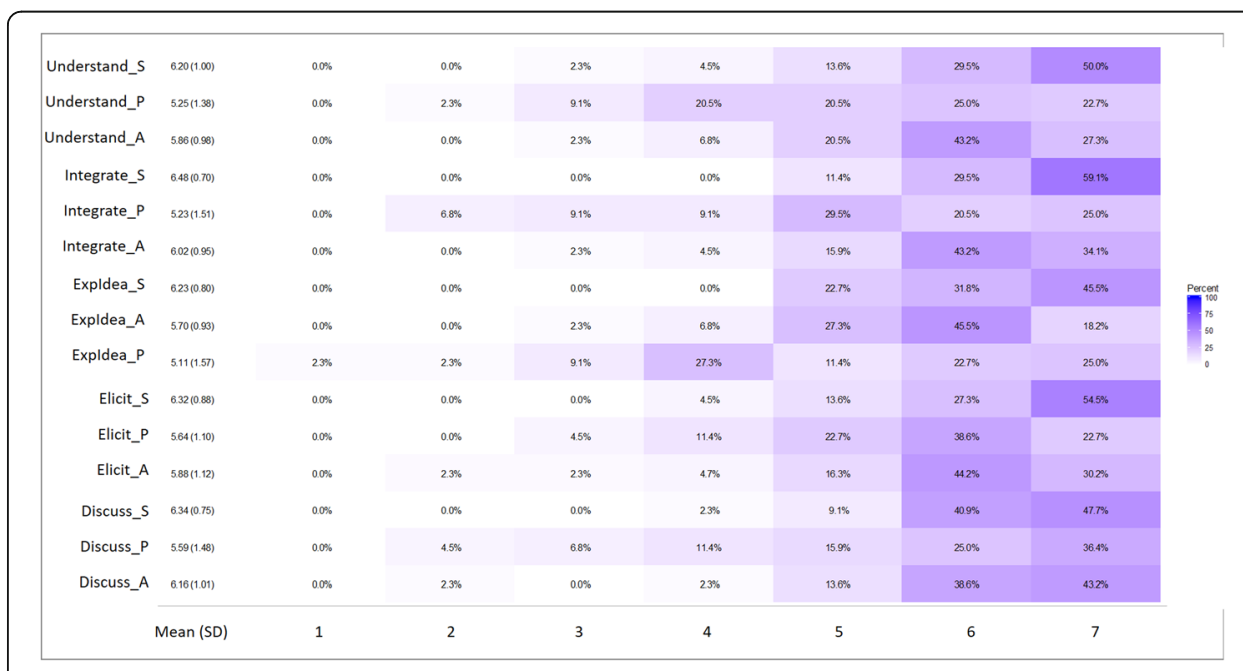

Fig. 11 Summary of students' responses to the close-ended questions 
concept map."). The KB links aided students in detecting alternatives perspectives as well (25.5\%, e.g., "It is interesting to see the variety of my friends' concepts and discussing it together."). Some students reported that they faced difficulties in integrating different perspectives (15\%), especially when they had many differences (6.4\%). Some students felt like it was challenging to reach a consensus $(12.8 \%$, e.g., "It is difficult to determine who was the most correct.").

\section{Discussion}

Following the proposed approach, students achieve high-quality group products. A possible factor contributing to better group outcomes is the interaction during discourse. The initial study of RKB presents that the pairs in the experimental groups demonstrate more exploratory talk when they discuss each other's ideas, compared to the pairs who were not using the system (Wunnasri et al. 2018a, 2018b). Exploratory talk is a type of talk in which partners engage in each other's ideas critically but constructively (Mercer 1996). Students might actively dig for information when they agreed on what the other party says or offers arguments and look for alternative solutions when they disagree. Exploratory talk is considered the most educationally relevant type of talk that helps groups to reason together and increase individual learning gain (Wegerif et al. 1999).

While creating an individual map is a method to express own understanding, the reconstruction activity is a method to understand the partner's point of view. Ideas exchange through the reconstruction of concept map components from a partner's map, and the discussion of difference maps could encourage understanding of the partner's representation (Wunnasri et al. 2018b). Comprehension of partner representation becomes visible. Even though the study of Engelmann and Hesse (2010) shows that the awareness of other knowledge might not necessarily affect the learning outcomes, it affects the process of knowledge construction to make it more effective because learners can reach consensus-building faster and no initial exploration is needed (Engelmann and Hesse 2010). An awareness tool regarding knowledge of the collaborating partner allows social comparisons and guides activities. Learners approximate and integrate each other's perspectives, synthesize their ideas, and jointly try to make sense of a task (Nastasi and Clements 1992).

The reconstruction does not only assist learners in understanding the partner's perspective but also reveals the similarities degree between a pair's prior knowledge. The correlation between the similarity of learners' individual maps and the number of matching and excessive links are .5283 and -.5205 , respectively. These findings are consistent with the previous study results suggesting that the similarity of learners' map is reflected on their KB visualization (Wunnasri et al. 2018a). Moreover, some students agree that the reconstruction of the partner's kit is an interesting activity to find out the partner's comprehension (27\%). They become aware of the similarities and differences between their perceptions (25\%). They also find new ideas or different representations from a similar idea (14.9\%).

The reconstruction activity also raised conflicts because the students have to review all map components and estimate the solution of their partners. After reconstruction, the system can illustrate a difference map to facilitate students' discussion. The students are then able to detect a discrepancy between their representations. Prior research demonstrates that irregular information triggers students to actively process and resolve conflicts, which subsequently 
compensates conceptual change and advancement of understanding (Chan et al. 1997). By showing a difference map, students may elicit relevant information from the partners, so that they can discuss to negotiate different understanding. This is a key step to resolve conflicts among group members. Finally, the creation of a join map is a means to integrate similarities and differences of individual knowledge and reach a consensus.

The results posit that, following the KB visualization, a clear majority of the students preserve the matching links, a moderate proportion of them maintain the lacking links, and more than half of the students preserve the excessive links in the group map with the portions of $82 \%, 42 \%$, and $60 \%$, respectively. The map scores gain has a moderate positive correlation with the number of excessive links. The students acknowledge the visualization from the KB map when they decompose a group map. Although the students keep the same link (relations), most of the linking words considerably differ in all types of KB links, which revealed that the students do not merely follow others' ideas, but also constructively build on the group shared knowledge.

In the $\mathrm{KB}$ approach, knowledge is made publicly accountable, and comprehension of others' perspectives is visible. Contrary to other approaches that can be only visible in the utterances (talks), comprehension and misunderstanding of partners' representation are not explicitly supported. The RKB is promising due to the reconstruction activity and the visualization of lacking and excessive links that could stimulate learners' progress on solving the task. By facing criticism, learners may be pushed to test multiple perspectives or to find more and better arguments for their positions (Chan et al. 1997). When building a consensus in a conflict-oriented manner, learners need to identify specific aspects of their peers' contributions and modify them or present alternatives. Thus, learners need to operate more closely in the reasoning of their peers when compared to a simple acceptance of peers' contributions (Chan et al. 1997). Prior studies indicate that active pursuit of resolving conflicts is necessary for the construction of knowledge (Kalishman et al. 2012; Roschelle 1992; Roschelle and Teasley 1995; van Boxtel et al. 2002). Both the visualization and clarification assist the discovery of discrepancies between individual knowledge representations, which provokes students to explain their reasoning and allows them to develop their resolution of differences through elaboration (van Boxtel et al. 2002). Learning effectiveness depends on the extent to which students share their learning; as a process of knowledge acquisition and creation through direct interaction (Stoyanova and Kommers 2002).

The current findings show that after following the RKB activities, most dyads can achieve high-quality group solutions and transfer their individual ideas, which are the representative forms of learning effectiveness at the group level as a whole and as an interaction between individual students and group achievements as stated by Stoyanova and Kommers (2002). Moreover, the students have also positively accepted the learning activities. The assessment of group performance is an important initial stage to identify the effectiveness of the RKB for collaborative learning. According to Dillenbourg (1999), the validity of group assessments can be understood in practical terms since the need for collaboration among professionals is increasing and any educational institution is required to improve the students' performance in collaborative situations. Furthermore, an investigation of learning effectiveness at the level of individual students and the interaction of group achievements with the individual post-collaboration outcomes is also interesting to uncover how the RKB approach affect conceptual change at the individual level. 


\section{Limitations of the study and directions for future studies}

This study is the first attempt to explore the potential use of the RKB system in a practical classroom in Indonesia. A single group study is conducted to ensure fairness in a real classroom context. Future studies may conduct an experimental study in order to measure the effectiveness of the $\mathrm{RKB}$ approach compare to a common collaborative concept mapping approach with individual externalization and concept map sharing. A within-subjects study with counterbalancing and group randomization can be a potential alternative for further research. To evaluate the effects of collaborative activities on individual knowledge, students would be requested to build post-collaboration maps or answer a pre- and post-test as parts of the experimental activities in the future. Moreover, the use of RKB in collaborative learning settings is administered in a dyad. The issue of how to transfer this approach to more than two people would be another subject of future research.

Most students consider the RKB approach is attractive and stimulating, while the lowest items are related to perspicuity scale. This may be because the students' cognitive loads are rather high. It is suggested differentiating the individual and collaborative phase to reduce the students' loads. Some students also report several technical issues. The interface of the RKB system may require some improvements. Further, an analyzer that shows students' generated links might be useful to provide information about students' progress for the teacher.

\section{Conclusion}

This study investigates the use of RKB approach to support collaborative knowledge construction, extending previous collaborative concept mapping approaches (de Weerd et al. 2017; Engelmann and Hesse 2010; Fischer et al. 2002; Gracia-Moreno et al. 2017) in two ways: by reconstruction of partner's kit and by the visualization of individual map differences. The study findings indicate that the combination of these activities supports learners to achieve high-quality collaborative products as in the previous collaborative concept mapping studies with individual externalization and knowledge awareness tool. The visualization of map differences acts as a guide during discourse which is reflected from the patterns of modifications from the individual, i.e., initial and reconstruction maps, to the group maps. Positive attitudes of the students toward the activities signify the usefulness and attractiveness of the learning activities. The proposed approach provides a means for sharing of individual ideas and discovers the divergence of knowledge that has not been utilized in other studies. Though the results from this initial study seem promising, to infer the generalizability of the proposed approach more experiments in different classroom contexts and settings should be conducted.

Abbreviations

KB: Kit-Build; RKB: Reciprocal Kit-Build

Acknowledgments

There are no acknowledgments.

Authors' contributions

This study reported in this article is a part of the PhD project conducted by LS. TH is her main supervisor, and $\mathrm{YH}$ is her cosupervisor. An initial manuscript was written by LS. KJ and HBS have significant contribution to plan and prepare the materials for conducting the experiment, collecting the data, and reviewing the manuscript. WW and JP designed and 
developed the system for experimentation and provided feedback to analyze the data. Each named author has substantially contributed to conducting the underlying research. All authors read and approved the final manuscript.

\section{Funding}

This work was partially supported by JSPS KAKENHI Grant Numbers $19 \mathrm{H} 04227$ and 17H01839.

\section{Availability of data and materials}

Not applicable.

\section{Ethics approval and consent to participate}

Ethical approval is not applicable, but consent form to participate was obtained.

\section{Consent for publication}

Written consent form for publication was obtained.

\section{Competing interests}

The authors declare that they have no competing interests.

\section{Author details}

'Learning Engineering Laboratory, Department of Information Engineering, Hiroshima University, Hiroshima, Japan. ${ }^{2}$ Department of Computer Science, Faculty of Science, Khon Kaen University, Khon Kaen, Thailand. ${ }^{3}$ Department of Computer and Information Science, Faculty of Science and Engineering, Kasetsart University, Bangkok, Thailand. ${ }^{4}$ Digital Library and Distance Learning Laboratory, Faculty of Computer Science, Universitas Indonesia, Depok, Indonesia.

Received: 12 September 2019 Accepted: 30 June 2020

Published online: 31 July 2020

\section{References}

Baines, E., Rubie-Davies, C., \& Blatchford, P. (2009). Improving pupil group work interaction and dialogue in primary classrooms: results from a year-long intervention study. Cambridge Journal of Education, 39(1), 95-117. https://doi.org/10. 1080/03057640802701960.

Basque, J., \& Lavoie, M.-C.-. C. (2006). Collaborative concept mapping in education: major research trends. Concept Maps: Theory, Methodology, Technology. Proc. of the Second Int. Conference on Concept Mapping., 1, 79-86. Retrieved from http:// eprint.ihmc.us/119/

Beers, P. J., Boshuizen, H. P. A., Kirschner, P. A., \& Gijselaers, W. H. (2006). Common ground, complex problems and decision making. Group Decision and Negotiation. https://doi.org/10.1007/s10726-006-9030-1.

Chan, C., Burtis, J., \& Bereiter, C. (1997). Knowledge building as a mediator of conflict in conceptual change. Cognition and Instruction. https://doi.org/10.1207/s1532690xci1501_1.

Chen, W., Allen, C., \& Jonassen, D. (2018). Deeper learning in collaborative concept mapping: a mixed methods study of conflict resolution. Computers in Human Behavior, 87, 424-435. https://doi.org/10.1016/j.chb.2018.01.007.

Chiu, C. H. (2004). Evaluating system-based strategies for managing conflict in collaborative concept mapping. Journal of Computer Assisted Learning, 20(2), 124-132. https://doi.org/10.1111/j.1365-2729.2004.00072.x.

Chiu, C. H., Huang, C. C., \& Chang, W. T. (2000). The evaluation and influence of interaction in network supported collaborative concept mapping. Computers and Education, 34(1), 17-25. https://doi.org/10.1016/S0360-1315(99)00025-1.

Chiu, Chiu Hui, Wu, W. S., \& Huang, C. C. (2000). Collaborative concept mapping processes mediated by computer. WebNet World Conference on the WWW and Internet, 95-100.

Chung, G., O'Neil Jr., H. F., \& Herl, H. E. (1999). The use of computer-based collaborative knowledge mapping to measure team processes and team outcomes. Computers in Human Behavior, 15(3-4), 463-493.

Correia, P. R., Infante-Malachias, M. E., \& Godoy, C. E. (2008). From theory to practice: the foundations for training students to make collaborative concept maps. In Proceedings of the Third International Conference on Concept Mapping, (pp. 414-421)

Czerniak, C. M., \& Haney, J. J. (1998). The effect of collaborative concept mapping on elementary preservice teachers' anxiety, efficacy, and achievement in physical science. Journal of Science Teacher Education, 9(4), 303-320 https://doi.org/10.1023/ A:1009431400397.

de Weerd, J., Tan, E., \& Stoyanov, S. (2017). Fostering interdisciplinary knowledge construction in computer-assisted collaborative concept mapping. Lecture Notes in Computer Science (Including Subseries Lecture Notes in Artificial Intelligence and Lecture Notes in Bioinformatics), 10474 LNCS(Ccm), 391-396. https://doi.org/10.1007/978-3-319-66610-5_32.

Dillenbourg, P. (1999). What do you mean by "collaborative learning"? Collaborative Larning Cognitive and Computational Approaches, 1(6), 1-15 https://doi.org/10.1.1.167.4896

Engelmann, T., \& Hesse, F. W. (2010). How digital concept maps about the collaborators' knowledge and information influence computer-supported collaborative problem solving. International Journal of Computer-Supported Collaborative Learning, 5(3), 299-319. https://doi.org/10.1007/s11412-010-9089-1.

Fischer, F., Bruhn, J., Gräsel, C., \& Mandl, H. (2002). Fostering collaborative knowledge construction with visualization tools. Learning and Instruction, 12(2), 213-232. https://doi.org/10.1016/S0959-4752(01)00005-6.

$\mathrm{Gao}, \mathrm{H}$. (2008). The effects of key concepts availability and individual preparation in the form of proposition formation in collaborative concept mapping on learning, problem solving, and learner attitudes. Humanities and Social Sciences: Dissertation Abstracts International Section A.

Gao, H., Thomson, M., \& Shen, E. (2013). Knowledge construction in collaborative concept mapping: a case study. Journal of Information Technology and Application in Education, 2(1), 1-15 Retrieved from www.jitae.org. 
Gracia-Moreno, C., Cerisier, J.-F., Devauchelle, B., Gamboa, F., \& Pierrot, L. (2017). Collaborative knowledge building through simultaneous private and public workspaces. Data Driven Approaches in Digital Education, 10474, 553-556. https://doi.org/ 10.1007/978-3-319-66610-5.

Hayashi, Y., Murotsu, M., Yamamoto, S., \& Hirashima, T. (2017). Development and a practical use of monitoring tool of understanding of learners in class exercise. https://doi.org/10.1007/978-3-319-58524-6_3.

Herl, H. E., Baker, E. L., \& Niemi, D. (1996). Construct validation of an approach to modeling cognitive structure of US history knowledge. The Journal of Educational Research, 89(4), 206-218.

Hirashima, T., Yamasaki, K., Fukuda, H., \& Funaoi, H. (2015). Framework of kit-build concept map for automatic diagnosis and its preliminary use. Research and Practice in Technology Enhanced Learning, 10(1), 17. https://doi.org/10.1186/s41039-0150018-9.

lancu, M. (2014). Socio-cognitive conflict in learning Biology-challenge, solving and roles. Procedia - Social and Behavioral Sciences. https://doi.org/10.1016/j.sbspro.2014.03.214.

Jeong, H., \& Hmelo-Silver, C. E. (2016). Seven affordances of computer-supported collaborative learning: how to support collaborative learning? How can technologies help? Educational Psychologist, 51(2), 247-265. https://doi.org/10.1080/ 00461520.2016 .1158654

Junus, K., Sadita, L., \& Suhartanto, H. (2014). Social, cognitive, teaching, and metacognitive presence in general and focus group discussion: case study in blended e-learning Linear Algebra class. In Frontiers in Education Retrieved from http:// ieeexplore.ieee.org/abstract/document/7044247/.

Kalishman, S., Stoddard, H., \& O'Sullivan, P. (2012). Don't manage the conflict: transform it through collaboration. Medical Education. https://doi.org/10.1111/j.1365-2923.2012.04342.x.

Kasiyah, Sadita, L., Santoso, H. B., Soeradijono, S. H., \& Suhartanto, H. (2017). Assessing students' e-learning competencies in online learning environment. 2017 International Conference on Advanced Computer Science and Information Systems, ICACSIS 2017, 489-493. https://doi.org/10.1109/ICACSIS.2017.8355079

Kinchin, I. M., De-Leij, F. a. a. M., \& Hay, D. B. (2005). The evolution of a collaborative concept mapping activity for undergraduate microbiology students. Journal of Further and Higher Education, 29(1), 1-14. https://doi.org/10.1080/ 03098770500037655

Kitamura, T., Yamanaka, A., Maeda, K., Hayashi, Y., \& Hirashima, T. (2016). Comparison between kit-building task of concept map and multiple choice task of fill-in-the-blank question generated from the same series of propositions. In ICCE 2016 24th International Conference on Computers in Education: Think Global Act Local - Workshop Proceedings, (pp. 419-427).

Laugwitz, B., Held, T., \& Schrepp, M. (2008). Construction and evaluation of a user experience questionnaire. Lecture Notes in Computer Science (Including Subseries Lecture Notes in Artificial Intelligence and Lecture Notes in Bioinformatics). https://doi. org/10.1007/978-3-540-89350-9-6.

Limon, M. (2001). On the cognitive conflict as an instructional strategy for conceptual change: a critical appraisal. Learning and Instruction, 11, 357-380. https://doi.org/10.1016/S0959-4752(00)00037-2.

Mercer, N. (1996). The quality of talk in children's collaborative activity in the classroom. Learning and Instruction. https://doi. org/10.1016/S0959-4752(96)00021-7.

Nastasi, B. K., \& Clements, D. H. (1992). Social-cognitive behaviors and higher-order thinking in educational computer environments. Learning and Instruction. https://doi.org/10.1016/0959-4752(92)90010-J.

Nickerson, R. S. (1999). How we know - and sometimes misjudge - what others know: Imputing one's own knowledge to others. Psychological Bulletin, 125(6), 737-759. https://doi.org/10.1037/0033-2909.125.6.737.

Novak, J. D., \& Cañas, A J. (2008). The theory underlying concept maps and how to construct and use them. IHMC CmapTools, 1-36. https://doi.org/Technical Report IHMC CmapTools 2006-01 Rev 2008-01

Osmundson, E., Chung, G. K. W. K., Herl, H. E., \& Klein, D. C. D. (1999). Knowledge mapping in the classroom : A tool for examining the development of students' conceptual understandings. Office, 1522(310), 1-42.

Pailai, J., Wunnasri, W., Yoshida, K., Hayashi, Y., \& Hirashima, T. (2017). The practical use of Kit-Build concept map on formative assessment. Research and Practice in Technology Enhanced Learning, 12(1), 20. https://doi.org/10.1186/s41039-017-0060-x.

Roschelle, J. (1992). Learning by collaborating: Convergent conceptual change. Journal of the Learning Sciences. https://doi. org/10.1207/s15327809jis0203_1.

Roschelle, J., \& Teasley, S. D. (1995). The construction of shared knowledge in collaborative problem solving. In Computer supported Collaborative Learning. https://doi.org/10.1007/978-3-642-85098-1_5.

Roth, W., \& Roychoudhury, A. (1993). The concept map as a tool for the collaborative construction of knowledge: A microanalysis of high school physics students. Journal of Research in Science Teaching, 30(5), 503-534. https://doi.org/10 1002/tea.3660300508.

Santoso, H., Schrepp, M., Kartono, Y., Yudha, A., \& Priyogi, B. (2016). Measuring user experience of the student-centered elearning environment. The Journal of Educators Online. https://doi.org/10.9743/JEO.2016.1.5.

Stahl, G., Koschmann, T., \& Suthers, D. (2006). Computer-supported collaborative learning: an historical perspective. Cambridge Handbook of the Learning Sciences, 409-426. https://doi.org/10.1145/1124772.1124855.

Stoyanova, N., \& Kommers, P. (2002). Concept mapping as a medium of shared cognition in computer-supported collaborative problem solving. Journal of Interactive Learning Research. https://doi.org/10.1161/CIRCOUTCOMES.110. 942318.

Suthers, D. D. (2006). Technology affordances for intersubjective meaning making: a research agenda for CSCL. International Journal of Computer-Supported Collaborative Learning, 1(3), 315-337. https://doi.org/10.1007/s11412-006-9660-y.

van Boxtel, C., van der Linden, J., \& Kanselaar, G. (2000). Collaborative learning tasks and the elaboration of conceptual knowledge. Learning and Instruction, 10(4), 311-330. https://doi.org/10.1007/s40815-016-0287-5.

van Boxtel, C., van der Linden, J., Roelofs, E., \& Erkens, G. (2002). Collaborative concept mapping: provoking and supporting meaningful discourse. Theory Into Practice, 41(1), 40-46. https://doi.org/10.1207/s15430421tip4101_7.

Vygotsky, L. S. (1978). Mind in society: The development of higher psychological processes. https://doi.org/10.1007/978-3-54092784-6

Wang, M., Cheng, B., Chen, J., Mercer, N., \& Kirschner, P. A. (2017). The use of web-based collaborative concept mapping to support group learning and interaction in an online environment. Internet and Higher Education, 34, 28-40. https://doi. org/10.1016/j.iheduc.2017.04.003. 
Webb, N. M. (2009, March 1). The teacher's role in promoting collaborative dialogue in the classroom. British Journal of Educational Psychology, 79, 1-28. https://doi.org/10.1348/000709908X380772.

Wegerif, R., Mercer, N., \& Dawes, L. (1999). From social interaction to individual reasoning: an empirical investigation of a possible sociocultural model of cognitive development. Learning and Instruction. https://doi.org/10.1016/S09594752(99)00013-4.

Wunnasri, W., Pailai, J., Hayashi, Y., \& Hirashima, T. (2018a). Reciprocal Kit-Build concept map: an approach for encouraging pair discussion to share each other's understanding. IEICE Transactions on Information and Systems.

Wunnasri, W., Pailai, J., Hayashi, Y., \& Hirashima, T. (2018b). Reciprocal Kit-Building of concept map to share each other's understanding as preparation for collaboration. In Proceeding of the 19th International Conference on Artificial Intelligence in Education. London: United Kingdom.

Yoshida, K., Osada, T., Sugihara, K., Nino, Y., Shida, M., \& Hirashima, T. (2013). Instantaneous assessment of learners' comprehension for lecture by using kit-build concept map system. In International Conference on Human Interface and the Management of Information, (pp. 175-181).

\section{Publisher's Note}

Springer Nature remains neutral with regard to jurisdictional claims in published maps and institutional affiliations.

Submit your manuscript to a SpringerOpen ${ }^{\odot}$ journal and benefit from:

- Convenient online submission

- Rigorous peer review

- Open access: articles freely available online

- High visibility within the field

- Retaining the copyright to your article

Submit your next manuscript at $\boldsymbol{\nabla}$ springeropen.com 